\title{
Metastatic malignancy presenting initially as Acute Kidney Injury: Prospective follow up of six cases
}

\author{
Tania Mahbub ${ }^{1 *}$, Chowdhury Rifat Niger ${ }^{2}$, Salina Akter ${ }^{3}$, Rawshan Arra Khanam ${ }^{4}$
}

\begin{abstract}
:
Acute kidney injury (AKI) is a significant complication in patients with cancer and is associated with high morbidity and mortality. Rates of AKI vary in cancer patients on the basis of several factors, including types of malignancy (either solid tumor or hematologic), stage of malignancy, associated complications such as critical illness, and type of supportive or interventional therapy given to the patient. AKI is a common finding within the patients diagnosed as malignancy. However, AKI as initial presentation of malignant disease is uncommon. Six cases of metastatic malignancy presenting initially as acute kidney injury are reviewed in this prospective study. We have reviewed one case of metastatic small cell carcinoma of lung, one case of metastatic carcinoma of rectum, one case of metastatic carcinoma, of lung with Horner's syndrome, one case of metastatic pancreatic carcinoma and one case of metastatic squamous cell carcinoma of cervix. Out of them, two patients needed hemodialysis during hospital stay.
\end{abstract}

Key Words: AKI. Metastatic malignancy.

\section{Introduction}

Acute Kidney Injury (AKI) is a common complication in cancer patients. Operational definition of AKI is based on serum creatinine level according to AKIN (Acute Kidney Injury Network) criteria ${ }^{1}$. The criteria are described according to following stages. Stage 1 AKI : $>26.4$ micromole/L or $(0.3 \mathrm{mg} / \mathrm{dl})$ or an increase of serum creatinine $150 \%$ to $200 \%$ from the base line. Stage 2 AKI: An increasing serum creatinine $200 \%$ to $299 \%$ (2 to 3 folds increase from the baseline) Stage 3 AKI: An increase of serum creatinine 300\% of baseline or $>350$ micromole/l with an acute rise $45 \mathrm{micromole} / 1$ or patient required renal replacement therapy.

The largest cohort study of Danish cancer patients documented the highest rates of AKI in patients with kidney cancers at $44 \%$, myeloma at $33 \%$ and liver cancer at $31.8 \%{ }^{2}$ According to some studies, among the critically ill cancer patients, the rate of AKI is between $12 \%$ and $49 \%$, with $9 \%$ to $32 \%$ of patients requiring renal replacement therapy. $3,4,5$,

1. Consultant, Dept. of Nephrology, United Hospital Ltd, Gulshan 2, Dhaka.

2. Specialist, Dept. of Gastroenterology, United Hospital Ltd, Gulshan 2, Dhaka.

3. Specialist ,Dept of Nephrology, United Hospital Ltd, Gulshan 2,Dhaka

4. Consultant, Dept. of Respiratory Medicine, United Hospital Ltd, Gulshan 2, Dhaka

*Corresponding Author:

Dr. Tania Mahbub

MD (Nephrology)

Consultant,

Dept. of Nephrology,

United Hospital Ltd, Gulshan 2, Dhaka.

Email: taniaimran1@yahoo.com
Incidence of AKI in such cases can be as high as $30 \%$. Malignancy can affect kidneys in different ways. Pre renal AKI is seen in due to volume depletion; such as sepsis, vomiting and diarrhea, Hypercalcemia, Tumor lysis syndrome $^{6}$. In some cases, malignancy can cause intrinsic renal disease, like glomerulonephritis, Acute tubular Necrosis, Tumor infiltration and microangiopathy ${ }^{2,7,8}$. Other tumor may produce obstructive nephropathy due to bladder outlet obstruction and ureteral obstruction. The most common solid organ malignancies causing obstructive processes include bladder, prostate, uterus, and cervix malignancies. Ureteral obstruction can also occur in these settings, as well as because of external compression from retroperitoneal lymphadenopathy. ${ }^{2}$

Moreover, Kidneys are susceptible to injury especially after chemotherapy and radiotherapy and when the patient is critically ill. ${ }^{8}$ Patients usually develop kidney injury as the disease progress or in course of its treatment. However, AKI as initial presentation of metastatic malignancy is uncommon. Here we are going to present six cases where the initial presentations of metastatic malignancy was Acute Kidney Injury(AKI) and one case mimicked Rapidly Progressive Glomerulo -Nephritis (RPGN).

\section{Methods.}

This was a prospective observational study conducted in United Hospital between June 2018 and December 2019. All patients who had documented normal renal function in past 3 months before hospitalization and presented in hospital with AKI and incidentally diagnosed to have metastatic solid organ malignancy as the primary cause were included in the study.

After hospitalization base line serum creatinine level was recorded in each patients and serial serum creatinine were checked. Detail clinical history, investigation including past records and disease course during hospitalization were carefully noted for each patients. 
Bangladesh Crit Care J March 2020; 8 (1): 29-32

Ultra-sonogram of Kidney and urinary bladder region was done to exclude obstruction also to see kidney size and Cortico Medullary Differentiation (CMD).

Results.

Final diagnosis of malignancy, causes of AKI, presenting $\mathrm{S}$ creatinine level, requirement of dialysis and outcome were recorded in each case. (Table 1).

\section{Review of the cases.}

\section{CASE 1:}

A 78 years non diabetic, Hypertensive ex-smoker male had been referred to United Hospital for evaluation of acute kidney injury. There was no history of renal impairment before. After admission patient was thoroughly evaluated. On query there was significant weakness, occasional cough, loss of appetite and recurrent chest infection. Physical examination revealed mild dehydration and there was 3 small nodules on his skin, firm to hard in consistency and he stated these nodules appeared within 2 weeks. His serial serum creatinine was progressively increasing from 1.6 to $3.3 \mathrm{mg} / \mathrm{dl}$ and he developed AKI stage 2 according to AKIN criteria, Urine R/E showed bland urinary sediments. USG showed normal size kidneys with prominent parenchymal echogenicity with normal CMD without any feature of obstruction. Other investigations were normal. He had been treated as a case of pneumonia just before the admission. Recent CXR showed consolidation on left lung and all other laboratory reports are within normal range. As a suspected case of malignancy biopsy was taken from the skin nodule and that revealed metastatic small cell carcinoma of the lung. Chest CT revealed mass lesion on left upper lobe with erosion of Lt 5 th and 6th rib. The patient died within 7 days of the diagnosis.

\section{CASE 2:}

A 42 years young man was referred to United Hospital as a suspected case of rapidly progressive renal impairment with hypotension and got admitted to ICU. After initial settlement of his hemodynamic condition he required single session of HD for anuria and high Blood Urea Nitrogen (Cr- $6.5 \mathrm{mg} / \mathrm{dl}$, Urea $-99 \mathrm{mg} / \mathrm{dl})$. He gave history of recent NSTEMI one month back after that there was a short period of febrile illness for which he took cefixime orally for 7 days. There was no history of NSAID intake. All the secondary markers for GN were negative (ANA, Anti Ds DNA, C3 , C4, cANCA, pANCA and viral markers). Urine albumin2+, USG showed feature of Acute Kidney Injury with moderate ascites. Considering his unstable hemodynamic condition he underwent Methyl prednisolone for 3 consecutive days on empirical basis to protect his renal function as a suspected case of Rapidly Progressive Glomerulonephritis, pending his renal biopsy. His urine output became normal and serum creatinine went down rapidly. After 5 days his creatinine was 1.1 and urine output was approximately 3 to 4 liter per day. However his ascites didn't improved. CLD had been excluded by fibroscan of liver and upper GI endoscopy and the patient was vaccinated against HBV. Ascitic fluid study revealed exudative in nature, no AFB, negative for TB gene Xpert and malignant cell. For evaluation of his ascites we did CT abdomen without contrast and that revealed osteolytic lesion in sacrum with peritoneal seedling. Later proctoscopy showed a growth in rectum. The patient then went abroad for further management. During his hospital stay he developed stage 3 AKI according to AKIN criteria and required dialysis.

Table 1:

\begin{tabular}{|c|c|c|c|c|c|c|}
\hline $\begin{array}{l}\text { Name of } \\
\text { Malignancy }\end{array}$ & $\begin{array}{c}\text { Age of patient } \\
\text { (years) }\end{array}$ & $\begin{array}{c}\text { Gender } \\
(\mathrm{M}=\text { male, } \\
\mathrm{F}=\text { Female })\end{array}$ & $\begin{array}{c}\text { Creatinine at } \\
\text { presentation } \\
(\mathrm{mg} / \mathrm{dl})\end{array}$ & $\begin{array}{c}\text { Dialysis } \\
\text { Requirement }\end{array}$ & $\begin{array}{c}\text { Cause of } \\
\text { renal failure }\end{array}$ & $\begin{array}{c}\text { Outcome } \\
\text { during } \\
\text { Hospital stay }\end{array}$ \\
\hline $\begin{array}{l}\text { Bronchogenic } \\
\text { Carcinoma }\end{array}$ & 78 & $\mathrm{M}$ & 1.6 & Not required & $\begin{array}{l}\text { Dehydration } \\
\text { Pain killer } \\
\text { ingestion }\end{array}$ & Died \\
\hline Ca- Rectum & 42 & M & 6.5 & Required & $\begin{array}{c}\text { Exact cause unknown, } \\
\text { presentation was } \\
\text { like RPGN }\end{array}$ & $\begin{array}{l}\text { Went abroad } \\
\text { for treatment }\end{array}$ \\
\hline $\begin{array}{l}\text { Bronchogenic } \\
\text { Carcinoma }\end{array}$ & 56 & M & 2.5 & Not required & $\begin{array}{l}\text { Dehydration } \\
\text { Pain killer } \\
\text { ingestion }\end{array}$ & Palliative care \\
\hline $\begin{array}{l}\text { Renal cell } \\
\text { carcinoma }\end{array}$ & 64 & $\mathrm{~F}$ & 2.5 & Not required & $\begin{array}{c}\text { Primary malignancy } \\
\text { with renal vein } \\
\text { invasion }\end{array}$ & Died \\
\hline $\begin{array}{l}\text { Pancreatic } \\
\text { carcinoma }\end{array}$ & 72 & $\mathrm{~F}$ & 2.8 & Not required & $\begin{array}{l}\text { Uncontrolled } \\
\text { Diabetes, } \\
\text { Dehydration }\end{array}$ & Palliative care \\
\hline Carcinoma cervix & 70 & $\mathrm{~F}$ & 12 & Required & $\begin{array}{l}\text { Obstructive } \\
\text { Nephropathy } \\
\text { Analgesic use }\end{array}$ & Palliative care \\
\hline
\end{tabular}




\section{CASE 3:}

A 56 years normotensive non diabetic male from Barisal had been referred for recent onset of renal failure. His serum creatinine on admission was 2.5 but the creatinine was gradually rising. Previous urine $\mathrm{R} / \mathrm{E}$ showed protein $2+$. All other reports were within normal range. On examination patient was extremely emaciated and there was partial ptosis on his left eye. On query there was significant weight loss within short period along with neck pain. Careful examination of eye showed constricted pupil, enopthalmos. His CXR showed a faint shadow on left apex. Assuming a case of Bronchial carcinoma with Horner's syndrome, CT scan of chest, neck \& abdomen were done along with CT guided FNAC from the chest lesion. CT showed mass lesion in upper lobe of left lung with multiple rib erosion and spinal stenosis with possible adrenal metastasis. The patient later referred to Oncology for palliative management. During hospital stay he developed stage 2 AKI according to AKIN criteria

\section{CASE 4:}

64 years old diabetic \& hypertensive female with ischemic heart disease on anti- ischemic medication was presented to outpatient department with incidental finding of raised serum creatinine level, which was $2.5 \mathrm{mg} / \mathrm{dl}$. General examination revealed moderate anaemia. Systemic examination revealed normal. Urine R/E- Numerous RBC, Dysmorphic RBC only $5 \%$ : USG of whole abdomen : Asymmetric kidney Size ,Left side $13.5 \mathrm{~cm} \&$ Right Side $11.2 \mathrm{~cm}$ without any feature of obstruction. For further evaluation we advised CT scan of abdomen but patient couldn't afford it due to economic constraint. Her anti- platelet medications were kept on hold temporarily \& repeat Urine examination showed RBC: 20 /HPF. We advised repeat USG of abdomen \& Renal Function Tests but she missed the schedule. Within 3 weeks she admitted with severe Shortness of breathing. CXR shows Cannon ball shadow in both lungs. CT chest showed -Multiple metastasis of lung, CT scan of abdomen revealed Renal Cell Carcinoma of left Kidney with invasion in to left renal vein \& inferior vena-cava. We referred her to oncology department for palliative management. Patient developed stage 2 kidney injury as per AKIN criteria

\section{CASE 5:}

A 72 years diabetic, normotensive lady presented with hematuria and found to have uncontrolled DM with AKI ( $\mathrm{S} \mathrm{Cr}$ $2.8 \mathrm{mg} / \mathrm{dl}$ ) at emergency. She was deeply unconscious, blood sugar was $21 \mathrm{mmol} / \mathrm{l}$, planter bilateral extensor and diagnosed as hyperosmolar hyperglycemic state (HHS) and managed accordingly. Her blood sugar improved along with her renal function. However, USG showed dilated CBD with normal LFT and abdominal CT showed mixed echogenic carcinoma head of pancreas along with increased kidney dimensions, particularly in the right renal midsection; decreased cortex-medulla distinction; thinning at the middle and inferior part of the cortex; and a patch-like lesion lacking a clear image extending from the renal pelvis to the cortex. Patient attendent refused any active intervention and went for palliative management. Although pancreatic cancer rarely results in renal metastasis, renal involvement may occur in the form of invasion to the adjacent left kidney. In the present case, pancreatic cancer metastasis to the right kidney in the form of a single lesion was identified after the patient presented to the hospital for hematuria. Complaints of hematuria are rare in this patient population. Furthermore, renal metastases are multi focused, with lesions smaller than 3 $\mathrm{cm}$, and do not cause deterioration of renal contours. During her hospital course of illness she developed stage 2 kidney injury as per AKIN criteria

\section{CASE 6:}

A 70 year old pleasant postmenopausal lady presented with nausea and vomiting, referred to united hospital as AKI. At presentation her serum creatinine was $12 \mathrm{mg} / \mathrm{dl}$, urea $155 / \mathrm{dl}$, Urine output $700 \mathrm{ml} / 24$ vhours. On query for systemic symptoms she admitted occasional passage of per vaginal bleeding for last six months which she ignored. USG showed features of obstructive nephropathy with bilateral hydro uretero nephrosis. Per vaginal examination revealed large mass which bleeds on touch. Biopsy was taken from the mass, along with stenting of the ureter to relieve the ureteric obstruction. Her urine output increased with reduced S. creatinine $2.6 \mathrm{mg} / \mathrm{dl}$. However her biopsy revealed squamous cell carcinoma of cervix, with bladder invasion. PET -CT scan showed metastasis to lung and ribs. Patient underwent palliative treatment. Patient had stage 3 AKI and required renal replacement therapy during her hospital stay but renal function improved after giving bilateral ureteric stents.

\section{Discussion:}

Malignancy may affect renal function in different ways. In our setting, although it was difficult to find out the exact cause, possibly many factors played role in the development of AKI. In case 1 and case 3 both patients had taken analgesics for chronic pain. They also had dehydration and infection. One article stated that sepsis, vomiting, dehydration and infection are important causes of pre-renal AKI in cancer patients. ${ }^{6,9}$

Pancreatic carcinoma patient had uncontrolled blood sugar and was dehydrated. High blood sugar led to infection and HHS associated Dehydration may explain her impaired kidney function. According to some study malignancy can causes Thrombotic Micro Angiopathy (TMA) also. The most common malignancies associated with TMA that causes kidney injury, include gastric, breast, lung, prostate, and pancreas cancer; $5.7 \%$ of patients with metastatic cancers have TMA. ${ }^{10,11}$ In case 2 (Rectal carcinoma) patient presented as RPGN like presentation and responded well to injectable methylprednisolone. His urine output increased and renal function became normal. That indicated underlying immune mediated process.

In case of cervical carcinoma patient, there was obstructive nephropathy due to bilateral ureteric obstruction. She also had prior history of pain killer ingestion for chronic pelvic pain. Post renal AKI due to obstructive processes is seen more commonly in malignancies than in the general population. ${ }^{12}$

In renal cell carcinoma, malignancy itself causes AKI. The 
Bangladesh Crit Care J March 2020; 8 (1): 29-32

largest cohort study of Danish cancer patients documented the highest rate of AKI in patients with kidney cancers at $44 \%$. Intrinsic causes of AKI in cancer patients include primary glomerular disease, ATN due to toxins or ischemia, infiltrative processes, and micro angiopathic processes. ${ }^{8}, 11,13$

There might be other causes of AKI in above cases that we could not detect in our study. According to Pollack et.al ${ }^{14}$ primary organs causing renal metastases are lungs, breast, gastrointestinal tumors, malignant melanoma, and gynecologic and hematologic malignancies. Although these metastases generally occur hematogenously, some metastases are believed to spread to the adjacent organs from the colon, adrenal gland, and rarely from the pancreas. In a series of 5000 autopsies, Klinger et al. ${ }^{15}$ found 17 cases of renal metastasis from lung cancer, 11 from stomach cancer, 9 from breast cancer, 7 from pancreatic cancer, 4 from esophageal cancer, 7 from other gastrointestinal malignancies, and 1 from malignant melanoma.

Renal metastases from solid tumors to both kidneys rarely result in acute renal failure (ARF). One article discussed five cases, including one pulmonary cancer, causing ARF from extensive tissue replacement and destruction. In a separate case, ARF resulted from lymphatic metastases rather than from parenchymal destruction or obstruction ${ }^{7}$

In our cases there were no role of cancer chemotherapy and radiotherapy, as they were diagnosed incidentally as patients of malignancy during the evaluation of their acute kidney injury.

Although the initial presentations were AKI, unfortunately, all of them were already at the advanced stage of their diseases which was not commonly observed. Sadly, many of them had some sign symptoms of underlying malignancy before their presentation and could have been lifesaving if those were picked up in early stage.

In case 1, unresolved pneumonia at the back ground history of occasional cough in an old ex- smoker could have been a clue for underlying malignancy.

In case 3 , patient presented at his late stage. However, there was clear history of recent and rapid weight loss and neck pain, which could suggest malignancy.

In case 4, hematuria with asymmetrical kidney size sonographically in an elderly woman one should search for urogenital malignancy, especially in renal cell carcinoma. CT abdomen would have been lifesaving.

In case 6 per vaginal bleeding in postmenopausal lady should always be investigated for underlying malignancy. In our setting patient ignored her PV bleeding resulting in obstructive nephropathy and distant metastasis.

Among the six patients, two needed dialysis. Mortality rates usually range from $72 \%$ to $85 \%$ when renal replacement therapy is needed. ${ }^{2}$

\section{Conclusion:}

AKI is a common complication of Metastatic malignancy. However, Initial presentation of metastatic solid organ malignancy as AKI is rare. When presented with AKI, prognosis is poor as most of the patients present at later stage of their diseases. Therefore, high degree of suspicion \& aggressive search to detect malignancy at earlier stage is required to prevent distant metastasis. Early diagnosis may result in reversible AKI, if the tumor is amenable to chemotherapy or irradiation.

\section{References:}

1. Lopes JA, Sofia Jorge S. The RIFLE and AKIN classifications for acute kidney injury: a critical and comprehensive review. Clinical Kidney Journal, February 2013, 6(1): 8-14

2. Christiansen CF, Johansen MB, Langeberg WJ, Fryzek JP, Sorensen HT. Incidence of acute kidney injury in cancer patients: a Danish population-based cohort study. Eur J Intern Med. 2011; 22: 399-406

3. Darmon, M, Ciroldi M, Thiery G, Schlemmer B, Azoulay E. Clinical review: specific aspects of acute renal failure in cancer patients. Crit Care. 2006; 10: 211

4. Joannidis M. and Metnitz PG. Epidemiology and natural history of acute renal failure in the ICU. Crit Care Clin. 2005; 21: 239-249

5. Lameire, N., Van Biesen, W., and Vanholder, R. The changing epidemiology of acute renal failure. Nat Clin Pract Nephrol. 2006; 2: $364-377$

6. Lameire, N., Van Biesen, W., and Vanholder, R. Acute renal problems in the critically ill cancer patient. Curr Opin Crit Care. 2008; 14: 635-646

7. Campbell GA, Hu D, Okusa MD. Acute Kidney Injury in the Cancer Patient. Advances in CKD. Jan 2014; 21(1): 64-71

8. Benoit DD. and Hoste EA. Acute kidney injury in critically ill patients with cancer. Crit Care Clin. 2010; 26: 151-179

9. Stewart AF. Clinical practice. Hypercalcemia associated with cancer. N Engl J Med. 2005; 352: 373-379

10. Darmon M, Thiery G, Ciroldi M. et al. Intensive care in patients with newly diagnosed malignancies and a need for cancer chemotherapy. Crit Care Med. 2005; 33: 2488-2493

11. Lohrmann, HP, Adam W, Heymer B, and Kubanek B. Microangiopathic hemolytic anemia in metastatic carcinoma. Report of eight cases. Ann Intern Med. 1973; 79: 368-375

12. Humphreys BD, Soiffer RJ, Magee CC. Renal failure associated with cancer and its treatment: an update. J Am Soc Nephrol. 2005; 16: $151-161$

13 Lam, AQ, Humphreys BD. Onco-nephrology: AKI in the cancer patient. Clin J Am Soc Nephrol. 2012; 7: 1692-1700

14. Pollack HM, Banner MP, Amendola MA. Other malignant neoplasms of the renal parenchyma. Semin Roentgenol. 1987; 22(4):260-74

15. Klinger ME. Secondary tumors of the genito-urinary tract. J Urol. 1951; 65:144-53. 